\title{
Development of Hydrogen Electrode for Alkaline Fuel Cell-1
}

\author{
Khemraj Barhate ${ }^{1}$, Madhuri Sharon ${ }^{2}$, L.N. Singh ${ }^{3}$ and Maheshwar Sharon*,2 \\ ${ }^{I}$ Nanotechnology Research Center, Birla College, Kalyan 421304, India \\ ${ }^{2}$ NSN Research Center for Nanotechnology \& Bionanotechnology, SICES Degree College, Ambernath (W) 421505, \\ India \\ ${ }^{3}$ Department of Physics, Babasaheb Ambedkar Technical University, Lonere, Maharashtra
}

\begin{abstract}
In this paper an alkaline fuel cell (AFC), which was developed using nickel electro-catalyst for hydrogen oxidation process is reported. Pumice plate with porosity of $71 \%$ was used as an electrode substrate, and it was made by depositing conducting carbon using CVD process. Nickel metal was electroplated over the carbon deposited pumice plate. Carbon nanotubes were deposited over the electroplated nickel to prevent nickel from getting corroded by $\mathrm{KOH}$ solution (electrolyte). It is observed that $1.9 \mathrm{wt} \%$ nickel gives the best stability giving $300 \mathrm{~mA} / \mathrm{cm}^{2}$ current density at $980 \mathrm{mV}$ as hydrogen dissociation voltage. I-E characteristics and chronoamperometric studies of half and full cells are also reported.
\end{abstract}

Keywords: Alkaline Fuel Cell (AFC), nickel for hydrogen electrode, pumice plate as electrode, CNT deposition, conducting carbon.

\section{INTRODUCTION}

Fuel cells are electrochemical devices that convert the chemical energy of a reaction directly into electrical energy. Depending on the type of electrolyte used fuel cells are classified in different groups. One of them is alkaline fuel cell (AFC) that uses $\mathrm{KOH}$ as an electrolyte; it is easy to handle and has high electrical efficiency and operates at low temperature. In AFC, hydrogen and oxygen from air are used as the fuels. There are extensive reviews on AFC [1-3]. In spite of various advantages, it has not become popular because of constraints like use of $\mathrm{KOH}$ solution, which gets converted into $\mathrm{K}_{2} \mathrm{CO}_{3}$ by $\mathrm{CO}_{2}$ present in the air. $\mathrm{K}_{2} \mathrm{CO}_{3}$ is insoluble in $\mathrm{KOH}$ electrolyte and gets deposited on the pores of electrode, thus, obstructing the functioning of the electrode. Nevertheless, many efforts are being made to overcome this problem [4]. Another problem is, developing a porous electrode that is chemically stable at higher concentration of $\mathrm{KOH}$.

To assist the reaction at the electrode, electrocatalysts like platinum, nickel, iron and cobalt were used $[5,6]$. Chatterjee et al. [7-9] have pointed out that $\mathrm{Pt}, \mathrm{Ni}, \mathrm{Fe}$ and $\mathrm{Co}$ as well as their alloys (as catalysts for hydrogen electrode) can be deposited on carbon coated pumice stone for an AFC using $30 \% \mathrm{KOH}$ solution. The maximum current capacity reported by them is in the range of $230 \mathrm{~mA} / \mathrm{cm}^{2}$. It was observed that non noble metal like nickel could give as much current as obtained with platinum. However, they were not able to establish the relationship between the current capacities and the quantity of nickel electroplated on the electrode. In this paper we report the effect of metal concentration (i.e. nickel deposited on the pumice substrate) on the current capacity of the hydrogen electrode.

*Address correspondence to this author at the NSN Research Center for Nanotechnology \& Bionanotechnology, SICES Degree College, Ambernath (W) 421505, India; Tel: 91(251)2680800; Fax: (91) 0251 2680800;

E-mail: sharon@iitb.ac.in

\section{EXPERIMENTAL}

\subsection{Preparation of Suitable Electrode}

Pumice stone was used for making electrode because of its mechanical strength, light weight and large porosity [8]. Pumice stones were cut into $2 \times 2 \times 0.3 \mathrm{~cm}^{3}$ plates (Fig. 1A). Porosity was measured by water displacement method and found to be about $71 \%$. Pore's diameter was analyzed by Scanning Electron Microscopy (SEM-JEOL-JSM-840) (Fig. 1B) and was found to be in the 40 to $80 \mu \mathrm{m}$ range. Chemical analysis of pumice stone by Energy Dispersive X-Ray (EDX) (Philips CM-200) suggested that the major constituents were silica (40.5\%), $\mathrm{Al}(13.1 \%)$ and $\mathrm{Ca}(5.3 \%)$.

\subsection{Carbon Deposition on Pumice Stone by CVD Method}

Conducting carbon was deposited on the pumice stone to make it conductor, so that metal catalyst can be deposited onto it. Carbon deposition was done by a chemical vapor deposition (CVD) method $[10,11]$. Turpentine oil was used as the precursor for deposition of carbon. SEM micrograph of pumice plate deposited with carbon is shown in Fig. (1D).

\subsection{Deposition of Metal Catalyst on the Carbon Coated Pumice Stone}

Nickel metal was electroplated on the carbon deposited pumice plate. For electro-deposition of nickel, a cell having "carbon coated pumice stone // metal salt solution / Pt", configuration was used. The amount of catalyst that was electroplated over carbon-coated pumice electrode was calculated by applying a constant current for a known time. For this purpose Faradic efficiency of deposition was considered to be $100 \%$. After the deposition, carbon coated pumice electrode was kept in hydrogen atmosphere at $450^{\circ} \mathrm{C}$ for 3 hours to reduce metal oxide that might have formed during the process. Since pumice plate was porous, the amount of nickel deposited over the plate was calculated by using equation 1

2011 Bentham Open 

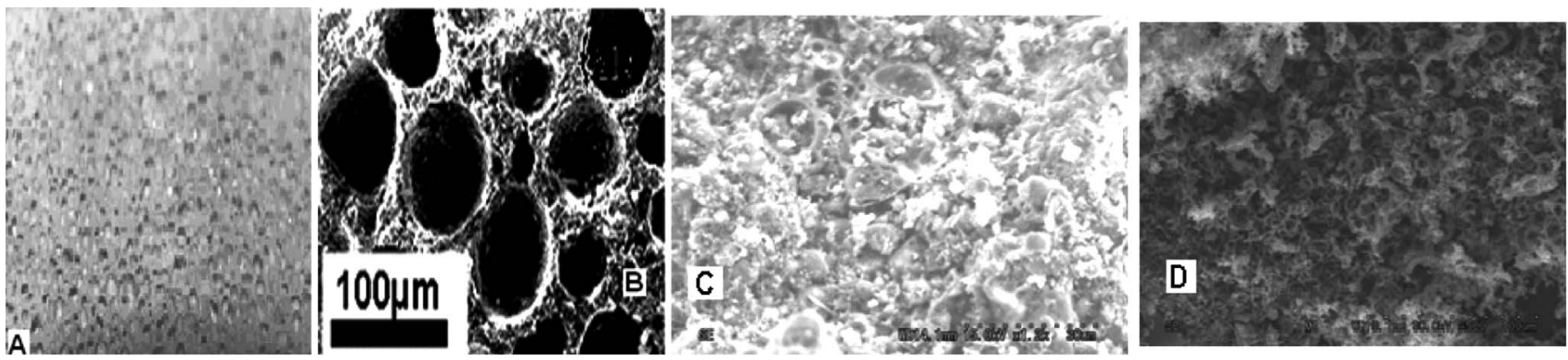

Fig. (1). (A) Photograph of a pumice plate (B) SEM micrograph showing pores in the range of 40 to $80 \mu \mathrm{m}$, (C) nickel electroplated over pumice plate and (D) CNT deposited over plate C.

Percentage weight of nickel deposited $=\left(\mathrm{W}_{1} / \mathrm{W}_{2}\right) 100(1)$

Where,

$\mathrm{W}_{1}$ = weight of deposited nickel calculated by assuming $100 \%$ Faradic efficiency and

$\mathrm{W}_{2}$ = weight of carbon deposited pumice plate before deposition of nickel

The carbon coated pumice plate hereafter is referred to as hydrogen electrode. A typical SEM micrograph of nickel deposited over pumice plate is shown in Fig. (1C). The sheet resistance of this electrode was in the range of $0.25-0.73$ $\Omega \mathrm{cm}^{-2}$. In order to protect nickel from getting corroded with $\mathrm{KOH}$ solution, carbon nanotubes (CNTs) were deposited by CVD process over the nickel.

\subsection{Electrochemical Performance of the Hydrogen Electrode}

The hydrogen dissociation voltage, half and full cell I-E characteristics and chronoamperometry of the half and full cell were measured using a potentiostat. Hydrogen dissociation voltage was measured using calomel electrode as reference electrode, platinum as counter electrode and hydrogen electrode as working electrode in a three-electrode cell of configuration "Hydrogen electrode / $\mathrm{H}_{2} / / 30 \% \mathrm{KOH} / \mathrm{SCE} /$ $\mathrm{Pt}$ ". Same configuration was used for half-cell I-E characteristics and chronoamperometry measurements.

For full cell characteristics, silver deposited carbon beads electrode (details will be published in subsequent paper) was used as the cathode and hydrogen electrode as an anode in a cell having - "Hydrogen electrode / $\mathrm{H}_{2} / / 30 \% \mathrm{KOH} / /$ Oxygen electrode $/ \mathrm{O}_{2}$ " configuration. To standardize the amount of nickel to be deposited onto the pumice plate, different amounts of nickel were deposited over the carbon deposited pumice electrodes.

\section{RESULTS AND DISCUSSIONS}

\subsection{Hydrogen Dissociation Voltage Measurements (Half Cell)}

The hydrogen dissociation voltage (HDV) obtained from the hydrogen electrodes coated with $\mathrm{Ni}$ metal of different amount is shown in Fig. (2). This graph suggests that highest HDV is obtained with hydrogen electrode containing nickel around $3.5 \mathrm{wt} \%$ giving hydrogen dissociation voltage of around $-980 \mathrm{mV} v s$. SCE.This value is in close consonance with that of the theoretically predicted value $(-1.058 \mathrm{~V} v s$ SCE)

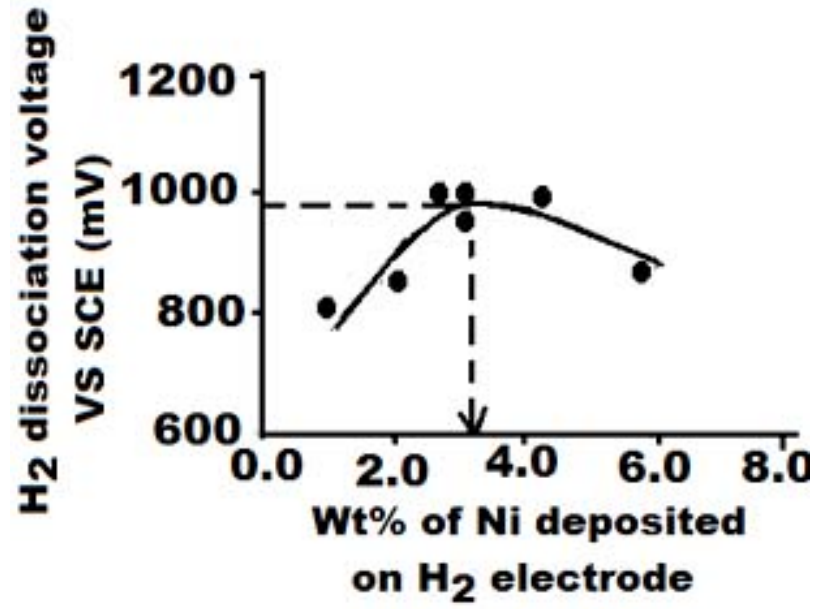

Fig. (2). Hydrogen dissociation voltage $(\mathrm{mV})$ with respect to SCE of electrodes coated with nickel.

\subsection{I-E Characteristics of Half Cell of Hydrogen Elec- trode}

Since for $30 \% \mathrm{KOH}$ solution the theoretical values of hydrogen dissociation voltage (HDV) with respect to SCE is $-1.058 \mathrm{~V}$ and for oxygen its value is $-0.17 \mathrm{~V}$ (approx.); the IE characteristics were measured in the range of $-1.2 \mathrm{~V}$ to -0.2 $\mathrm{V} v s$. SCE. Typical half cell I-E characteristics are shown in Fig. (3A). Single sweep of current -voltage was measured for cell having Hydrogen Electrode / $\mathrm{H}_{2} \| 30 \% \mathrm{KOH} / \mathrm{Pt}$ configuration. Potential of working electrode was measured with respect to SCE. This measurement was done with hydrogen electrode containing different amounts of nickel deposited on the electrode. A typical I-E curve obtained with hydrogen electrode containing $2 \mathrm{wt} \%$ nickel is shown in Fig. (3A).

The current density at zero potential was calculated from the I-E graphs obtained with various hydrogen electrodes containing different amounts of nickel. Results of these calculations are shown in Fig. (3B). Though there are few scattered points in the graph (Fig. 3B), the trend suggests that hydrogen electrode containing lower concentration of nickel (around $2 \mathrm{wt} \%$ ) may be useful for getting the maximum current density.

\subsection{Chronoamperometric Results of Half Cell of Hydro- gen Electrode}

Chronoamperometric measurement was carried out to observe stability of the electrode over a period of $1000 \mathrm{sec}-$ 
A

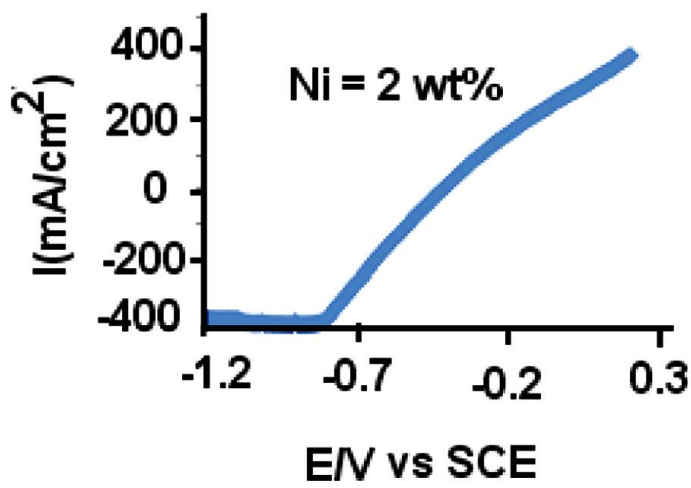

B

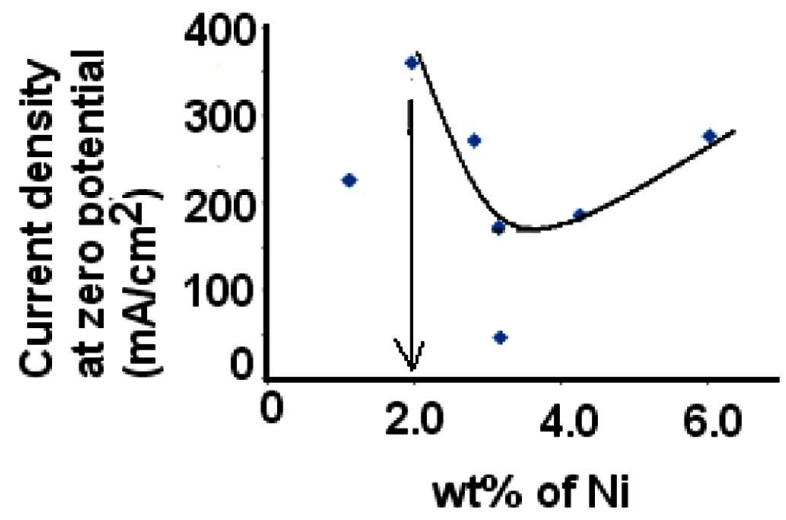

Fig. (3). (A) I-E Characteristics of Half cell ( Hydrogen Electrode / $\mathrm{H}_{2} \| 30 \% \mathrm{KOH} / \mathrm{Pt}$ ) at a scan rate of $50 \mathrm{mV} / \mathrm{s}$ for electrode containing 2 wt \% nickel and (B) Current density at zero potential obtained with hydrogen electrode containing different amounts of nickel.

onds. Chronoamperometry was measured at constant potential of $0.2 \mathrm{~V}$. The nature of a typical graph obtained with hydrogen electrode containing $2 \mathrm{wt} \%$ nickel is shown in Fig. (4). However, it is observed that current density is almost constant for all the hydrogen electrodes (figure not shown) suggesting that the electrodes were electrochemically stable over the period of $1000 \mathrm{~s}$.

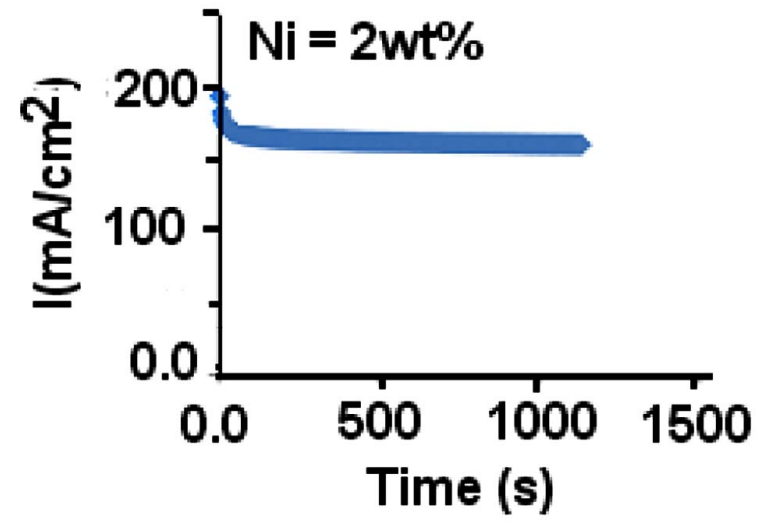

Fig. (4). Chronoamperometric characteristic curve of half Cell (Hydrogen electrode / $\mathrm{H}_{2} \| 30 \% \mathrm{KOH} / \mathrm{SCE}$ ) at $0.2 \mathrm{~V}$ for hydrogen electrode containing $2 \mathrm{wt} \%$ nickel.

\subsection{Full-Cell I-E Characteristics of Cell having Configu- ration "Hydrogen Electrode / $\mathrm{H}_{2} / / 30 \% \mathrm{KOH} / \mathrm{O}_{2} /$ Oxy- gen Electrode Containing Ag"}

In order to get an idea about working of full cell, experiments were carried out to get current -voltage characteristic and chronoamperometric result using hydrogen and oxygen electrodes. A typical I-E graph obtained with full cell with hydrogen electrode containing $1.9 \mathrm{wt} \%$ nickel is shown in Fig. (5A).

Fig. (5B) suggests that maximum current is obtained with hydrogen electrode having less than $2 \mathrm{wt} \%$ nickel deposition.

Results of trials for knowing the stability of electrode for 1000 seconds are presented in Fig. (6A). It shows that with $1.9 \mathrm{wt} \%$ nickel deposited on the hydrogen electrode it was stable for over 1000 seconds of constant use.
A
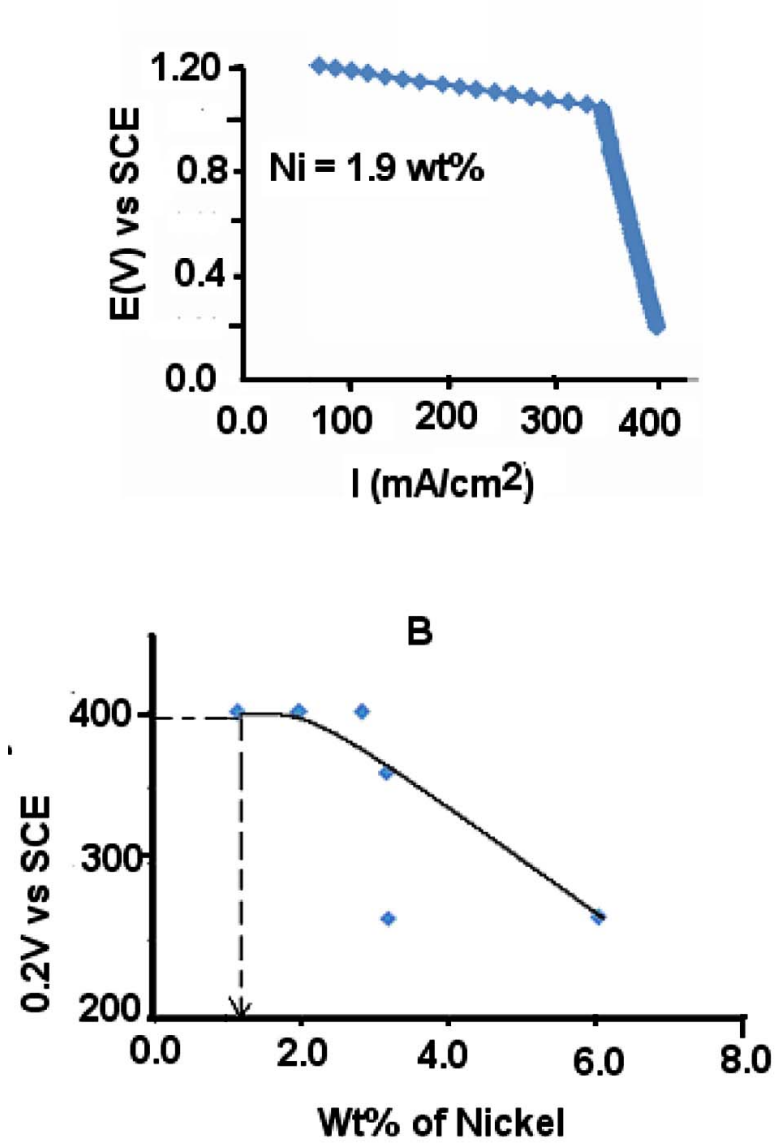

Fig. (5). (A) I-E characteristics of a full cell (Hydrogen electrode / $\mathrm{H}_{2}\|30 \% \mathrm{KOH}\|$ Oxygen electrode $/ \mathrm{O}_{2}$ ) at a scan rate $50 \mathrm{mV} / \mathrm{S}$ with hydrogen electrode containing $1.9 \mathrm{wt} \%$ nickel and (B) Current density at $0.2 \mathrm{~V} v s$. SCE obtained with hydrogen electrode containing different amounts of nickel with full cell using oxygen electrode.

Finally the current density at $0.2 \mathrm{~V} v s$. SCE obtained at 1000 s using hydrogen electrode containing different amounts of nickel (Fig. 6B) suggests that electrode is more stable with hydrogen electrode containing less than $2 \mathrm{wt} \%$ of nickel. 

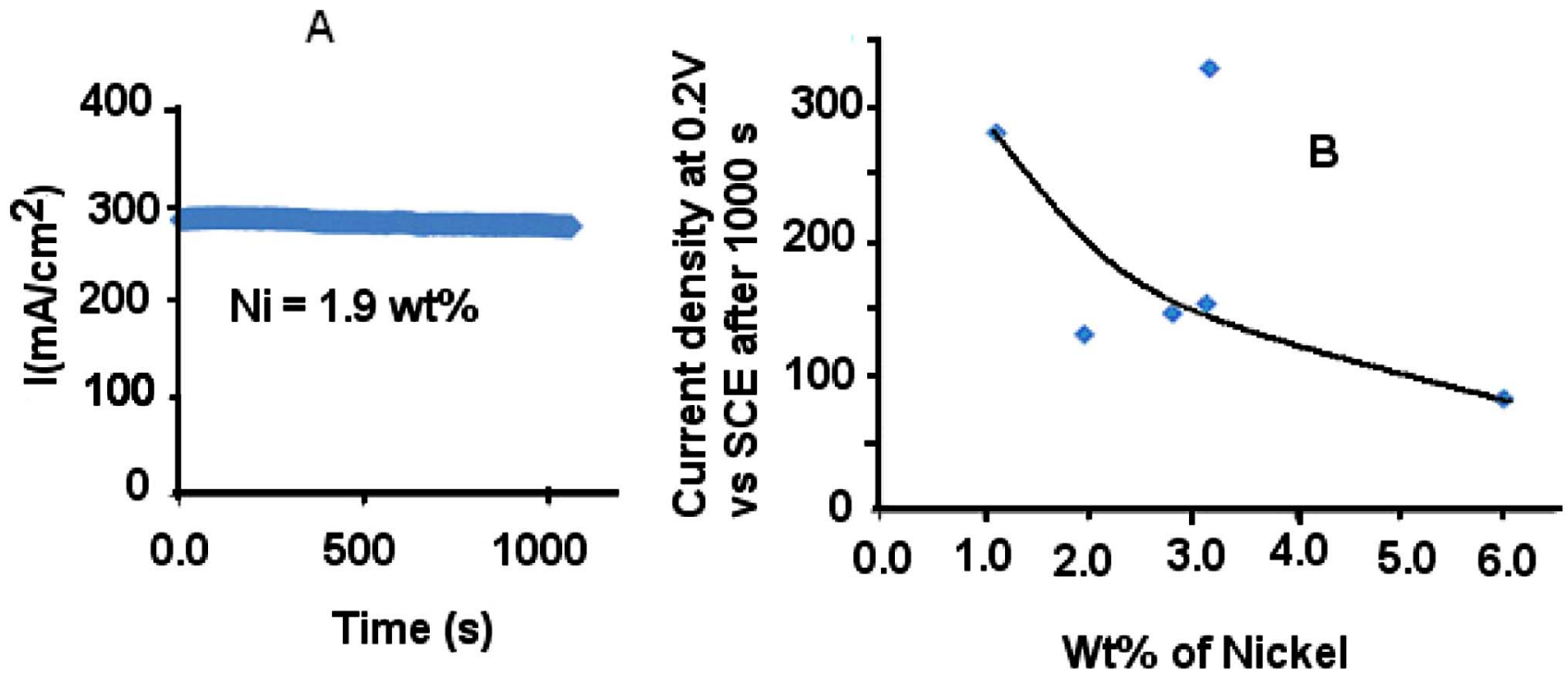

Fig. (6). (A) Chronoamperometry curve of full cell (Hydrogen electrode / $\mathrm{H}_{2}\|30 \% \mathrm{KOH}\|$ Oxygen electrode / $\mathrm{O}_{2}$ ) at $0.2 \mathrm{~V}$ obtained with hydrogen electrode containing nickel $1.9 \mathrm{wt} \%$ and (B) A graph showing the variation in current density at $0.2 \mathrm{~V}$ vs SCE for a full cell with hydrogen electrode containing different weight percentages of nickel.

\section{SUMMARY}

A Hydrogen electrode composed of pumice plate as substrate and nickel as electrocatalyst is developed for its use in AFC. Pumice plate had $71 \%$ porosity and the pore's diameters were in the $40-80 \mu \mathrm{m}$ range. Pumice plate was made by depositing conducting carbon followed by depositing different amounts of nickel electrocatalyst and finally carbon nanotubes were deposited to protect nickel from getting corroded by $30 \% \mathrm{KOH}$ electrolyte. Hydrogen oxidation behavior of this electrode was studied in the $30 \%$ $\mathrm{KOH}$ solution. Deposition of $1.9 \mathrm{wt} \%$ of nickel was found to be more stable (electrochemically) over a period of 1000s. Maximum current density of around $300 \mathrm{~mA} / \mathrm{cm}^{2}$ was obtained. Hydrogen dissociation voltage of $-980 \mathrm{mV}$ was very near to the theoretically expected value. However, we have not yet found the exact reasons for obtaining best result with 2 wt\% nickel. Research is being conducted to understand this behavior.

\section{CONFLICTS OF INTEREST}

None Declared.

\section{ACKNOWLEDGEMENT OF FUNDING}

None Declared.

\section{REFERENCES}

[2] Grietus, M.; Peter, C.; Adwin, M.; Jef, S.; The development of a $6 \mathrm{~kW}$ fuel cell generator based on alkaline fuel cell technology. Int. J. Hydrogen Energy, 2008, 33, 3220-3224.

[3] Betty, Y. S. L.; Donald, W. K.; Steven, J. T.; Performace of alkaline fuel cell: A possible future energy System? J. Power Sources, 2006, 161, 474-483.

[4] Tewari, A.; Sambhy, V.; Urquidi, M. M.; Sen, A.; Quantification of carbon dioxide poisoning in air breathing alkaline fuel cells. $J$. Power Sources, 2006, 153, 1-10.

[5] Gül. E.; Schulze, M.; Steinhilber, G.; Investigation of the degradation of different nickel anode types for alkaline fuel cells (AFCs). J. Power Sources, 2002, 106, 126-135.

[6] Joong-Pyo, S.; Yong-Suk, P.; Hong-Ki, L.; Ju-Seang, L.; Hydrogen oxidation characteristics of Raney nickel electrodes with carbon black in an alkaline fuel cell. J. Power Sources, 1998, 74, 151-154.

[7] Chatterjee, A. K.; Sharon, M.; Banerjee, R.; Alkaline fuel cell: carbon nanobeads coated with metals catalyst. J. Power Sources, 2003, 5251, 1-6.

[8] Chatterjee, A. K.; Sharon, M.; Banerjee, R.; Alkaline fuel cell: Carbon nanobeads coated with metal catalyst over porous ceramic for hydrogen electrode-1. J. Power Sources, 2003, 117, 39-44.

[9] Chatterjee, A. K.; Banerjee, R.; Sharon, M.; Enhancement of hydrogen oxidation activity at a nickel coated carbon beads electrode by cobalt and iron. J. Power Sources, 2004, 337, 216-221.

[10] Sharon, M.; Sharon, M.; Carbon Nanomaterials: Applications in Physico-chemical and Bio-Systems. Defense Sci. J., 2008, 58(4), 126.

[11] Mukul, K.; Xinluo, Z.; Yoshinori, A.; Sumio, I.; Sharon, M.; Kaori, H.; Carbon nanotubes from camphor by catalytic CVD. Mol. Cryst. Liq. Cryst., 2002, 387, 341-345.

Received: May 17, 2011

(C) Barhate et al.; Licensee Bentham Open.

This is an open access article licensed under the terms of the Creative Commons Attribution Non-Commercial License (http://creativecommons.org/licenses/by-nc/3.0/) which permits unrestricted, non-commercial use, distribution and reproduction in any medium, provided the work is properly cited. 